Article

\title{
Racial and Sex Differences in 24 Hour Urinary Hydration Markers among Male and Female Emerging Adults: A Pilot Study
}

\author{
William M. Adams ${ }^{1, *(D)}$, Derek J. Hevel ${ }^{1}$, Jaclyn P. Maher ${ }^{1}$ and Jared T. McGuirt ${ }^{2}$ \\ 1 Department of Kinesiology, University of North Carolina at Greensboro, Greensboro, NC 27412, USA; \\ djhevel@uncg.edu (D.J.H.); jpmaher@uncg.edu (J.P.M.) \\ 2 Department of Nutrition, University of North Carolina at Greensboro, Greensboro, NC 27412, USA; \\ jtmcguir@uncg.edu \\ * Correspondence: wmadams@uncg.edu; Tel.: +1-336-256-1455
}

Received: 20 February 2020; Accepted: 10 April 2020; Published: 12 April 2020

\begin{abstract}
The purpose of this study was to examine $24 \mathrm{~h}$ urinary hydration markers in non-Hispanic White $(\mathrm{WH})$ and non-Hispanic Black (BL) males and females. Thirteen males (BL, $n=6$; $\mathrm{WH}, n=7)$ and nineteen females (BL, $n=16, \mathrm{WH}, n=3$ ) (mean \pm SD; age, $20 \pm 4 \mathrm{y}$; height, $169.2 \pm 12.2 \mathrm{~cm}$; body mass, $71.3 \pm 12.2 \mathrm{~kg}$; body fat, $20.8 \pm 9.7 \%)$ provided a $24 \mathrm{~h}$ urine sample across $7(n=13)$ or $3(n=19)$ consecutive days ( $148 \mathrm{~d}$ total) for assessment of urine volume $\left(\mathrm{U}_{\mathrm{VOL}}\right)$, urine osmolality $\left(\mathrm{U}_{\mathrm{OSM}}\right)$, urine specific gravity $\left(\mathrm{U}_{\mathrm{SG}}\right)$, and urine color $\left(\mathrm{U}_{\mathrm{COL}}\right)$. $\mathrm{U}_{\mathrm{VOL}}$ was significantly lower in $\mathrm{BL}(0.85 \pm 0.43 \mathrm{~L})$ compared to WH college students $(2.03 \pm 0.70 \mathrm{~L})(p<0.001)$. Measures of $\mathrm{U}_{\mathrm{OSM}}, \mathrm{U}_{\mathrm{SG}}$, and $\mathrm{U}_{\mathrm{COL}}$, were significantly greater in BL $\left(716 \pm 263 \mathrm{mOsm} \cdot \mathrm{kg}^{-1}, 1.020 \pm 0.007\right.$, and $4.2 \pm 1.4$, respectively) compared to WH college students ( $473 \pm 194 \mathrm{mOsm} \cdot \mathrm{kg}^{-1}, 1.013 \pm 0.006,3.0 \pm 1.2$, and respectively) $(p<0.05)$. Differences in $24 \mathrm{~h}$ urinary hydration measures were not significantly different between males and females $(p>0.05)$ or between the interaction of sex and race/ethnicity $(p>0.05)$. Non-Hispanic Black men and women were inadequately hydrated compared to their non-Hispanic White counterparts. Our findings suggest that development of targeted strategies to improve habitual fluid intake and potentially overall health are needed.
\end{abstract}

Keywords: fluid intake; urine osmolality; urine volume; urine specific gravity; water consumption

\section{Introduction}

Water is an essential component for life and is intimately involved in maintaining normal physiologic function throughout the body. The complex and dynamic processes of total body water turnover and fluid regulation vary from person to person making it difficult to define a universal standard for daily adequate water intake [1-3]. However, entities such as the European Food Safety Authority (EFSA) [4] have developed adequate intake values of water for men (2.5 L/day) and women $(2.0 \mathrm{~L} /$ day $)$, which were derived from data assessing daily water consumption and a theoretical value for urine osmolality.

Recent epidemiological data has suggested a possible link between the volume of daily water intake and various health outcome measures. Increased consumption of water has been associated with a reduced risk of obesity, urinary tract infections, chronic kidney disease, cardiovascular disease, and a reduction in the incidence of hyperglycemia [5-11]. Despite these benefits, recent cross-sectional surveys have shown that $60 \%$ of men and $40 \%$ of women do not comply with the EFSA recommendations for daily water intake [12], which may alter the long-term health risk profile in persons who habitually consume low volumes of water on a daily basis [13,14]. Although $40 \%$ of women were found to 
not meet current EFSA standards, they were more than twice as likely to meet the adequate intake standards for daily fluid intake than that of men [12].

Furthermore, studies suggest that there are racial and ethnic differences surrounding fluid intake with non-Hispanic Blacks being inadequately hydrated compared to non-Hispanic Whites [15-17]. Kenney et al. [16], found that children who were non-Hispanic Black and/or a boy were more likely to be underhydrated than non-Hispanic Whites and girls, respectively. Similarly, Brooks et al. [15] observed that non-Hispanic Black adults were 1.4 times more likely than non-Hispanic White adults to be inadequately hydrated as measured by urine osmolality and assessment of total water intake in the participants' diet. Notwithstanding, in addition to racial/ethnic differences in water intake, factors such as age, sex, and level of physical activity may also contribute to observed differences [17].

However, these previous studies have been limited with regard to various aspects of the methodological approach $[18,19]$, which may inaccurately depict true racial and sex differences in daily hydration status. Specifically, there are two key limitations of this previous research. First, previous findings only utilized a spot urine sample, which is subject to circadian variation [20-22] and has been shown not to reflect $24 \mathrm{~h}$ hydration status. Moreover, $24 \mathrm{~h}$ urine osmolality has been proposed as measure to determine optimal hydration status as it provides an accurate assessment of total fluid intake [23]. By not utilizing a clinically validated method for assessing daily fluid intake and $24 \mathrm{~h}$ hydration status, previous results may not accurately depict a true assessment of daily hydration status across multiple days [24-26]. Second, while previous literature has largely focused on explaining hydration differences in a given population $[27,28]$, there is no known literature that has specifically looked at racial and sex differences in $24 \mathrm{~h}$ hydration status in emerging adults $(18-25 \mathrm{y})$.

Given the aforementioned limitations, gaining a better understanding of daily hydration status in emerging adults is needed. Emerging adulthood represents a critical time in life due to the transition from dependency on a caregiver to independence, which may result in the adoption of poor health behaviors. Therefore, the primary purpose of this study was to examine the racial and sex differences in $24 \mathrm{~h}$ urinary hydration measures in non-Hispanic Black and non-Hispanic White emerging adults. As a secondary aim, we sought to explore the interactions between sex and race on $24 \mathrm{~h}$ urinary hydration measures in this population.

\section{Methods}

\subsection{Participants}

Thirteen men (non-Hispanic Black (BL), $n=6$; non-Hispanic White $(\mathrm{WH}), n=7$ ) and nineteen women (BL, $n=16, \mathrm{WH}, n=3$ ) (mean $\pm \mathrm{SD}$; age, $20 \pm 4 \mathrm{y}$; height, $169.2 \pm 12.2 \mathrm{~cm}$; body mass, $71.3 \pm 12.2 \mathrm{~kg}$; body fat, $20.8 \pm 9.7 \%$ ) (see Table 1 for further participant characteristics) were recruited from a university in the southeastern United States to participate. Participants were excluded if they met any of the following exclusionary criteria: (1) evidence of clinically relevant diseases that may alter body water regulation, (2) previous surgery on the digestive tract that may impair the body's ability to normally regulate body water, and (3) actively attempting to gain or lose body weight, which may influence total water intake due to changes in caloric intake. In addition, female participants were excluded if they were currently pregnant. To assess race/ethnicity, all subjects that self-identified as non-Hispanic White or non-Hispanic Black were included. All participants were informed of the study requirements, benefits, and risks before providing written informed consent. This study was approved by the University of North Carolina at Greensboro's institutional review board (approval numbers, 18-0269 and 18-0063) prior to the commencement of any data collection. 
Table 1. Participant Demographics.

\begin{tabular}{ccccc}
\hline & \multicolumn{2}{c}{ Non-Hispanic White } & \multicolumn{2}{c}{ Non-Hispanic Black } \\
\cline { 2 - 5 } & Male $(\boldsymbol{n}=\mathbf{7})$ & Female $(\boldsymbol{n}=\mathbf{3})$ & Male $(\boldsymbol{n}=\mathbf{6})$ & Female $(\boldsymbol{n}=\mathbf{1 9})$ \\
\hline Age $(\mathrm{y})$ & $24 \pm 4$ & $24 \pm 3$ & $19 \pm 1$ & $19 \pm 1$ \\
Height (cm) & $173.9 \pm 17.1$ & $175.6 \pm 10.9$ & $169.1 \pm 8.6$ & $166.4 \pm 11.4$ \\
Nude Body Mass (kg) & $76.9 \pm 10.7$ & $72.5 \pm 13.7$ & $69.7 \pm 9.8$ & $69.6 \pm 10.1$ \\
Body Fat (\%) & $17.7 \pm 10.1$ & $21.3 \pm 9.2$ & $20.3 \pm 10.8$ & $20.9 \pm 10.2$ \\
\hline
\end{tabular}

\subsection{Procedures}

This study combined results from two separate studies that utilized an observational design where participants visited the laboratory for $7(n=13)$ or $3(n=19)$ consecutive days for 24 h hydration assessment. In total, $148 \mathrm{~d}$ (observations) of $24 \mathrm{~h}$ urine samples were collected amongst all participants for all days they were instructed to come to the laboratory. The study requiring participants to visit the laboratory on 3 consecutive days to drop off $24 \mathrm{~h}$ hydration assessment included one weekend day and two weekdays. During the initial visit to the laboratory, a trained research assistant took anthropometric measures and participants were instructed on the $24 \mathrm{~h}$ data collection procedures. Participants were provided with a clean container in which they were to void all urine produced over a $24 \mathrm{~h}$ timeframe. Participants were instructed to provide a complete urine void for each time point. For male participants, they were instructed to void directly into the $10 \mathrm{~cm}$ diameter opening of the clean container. For female participants, they were provided a graduated specimen pan (Model DYND36600, Medline Industries, Inc., Northfield, IL, USA) to void all urine. Following each void, female participants were instructed to pour the void into the clean container provided to them in order to seal and store the sample. Participants arrived the next morning to the laboratory, returned their $24 \mathrm{~h}$ urine sample and provided a nude body mass. Participants were given a clean specimen container and were instructed to repeat the same procedures daily for the length of the study.

To minimize individual variability and the influence of circadian rhythms in hydration status, all participants arrived at the laboratory to return urine collected in the previous $24 \mathrm{~h}$ between the hours of 0600-0900 each day with the timing of their arrival being $\pm 1 \mathrm{~h}$ from their initial visit. Participants were instructed to go about their normal daily routines during the urine collection periods to garner an ecologically valid assessment of their $24 \mathrm{~h}$ hydration status.

\subsection{Measurements}

Hydration Status. For assessment of hydration status, each $24 \mathrm{~h}$ urine sample was measured for urine volume $\left(\mathrm{U}_{\mathrm{VOL}}\right)$ using a digital scale to the nearest $0.0001 \mathrm{~kg}$ (Ranger 3000 , OHAUS Corporation, Parsippany, NY), urine osmolality ( $\mathrm{U}_{\mathrm{OSM}}$ ) performed in duplicate using freezing point depression (Model 3320, Advanced Instruments, Inc., Norwood, MA), urine specific gravity (U $\mathrm{U}_{\mathrm{SG}}$ ) (Reichert AR200, Reichert Technologies, Buffalo, NY), and urine color ( $\mathrm{U}_{\mathrm{COL}}$ ) [29]. For the purposes of this manuscript, euhydration was defined as a $\mathrm{U}_{\mathrm{OSM}}<500 \mathrm{mOsm} \cdot \mathrm{kg}^{-1}$ [23], $\mathrm{U}_{\mathrm{SG}} \leq 1.012$, and $\mathrm{U}_{\mathrm{COL}} \leq 4$ [30].

Body Composition. Nude body mass was measured to the nearest $0.1 \mathrm{~kg}$ using a digital scale (WB-800S Plus, Tanita Corporation, Tokyo, Japan) and height was measured to the nearest $0.1 \mathrm{~cm}$ using a wall-mounted stadiometer (Model 216, Seca, Chino, CA, USA). Body density was measured using the methods established by Jackson and Pollock [28,29]. The average of two skinfold measures (Lange Skinfold Calipers, Beta Technologies, Santa Cruz, CA) taken across three sites on the right side of the body were used; measures were taken at the chest, abdomen and thigh for men [31] and suprailiac, triceps, and thigh for women [32]. Body fat percentage was estimated using the method established by Siri [33]. 


\subsection{Statistical Analysis}

All data analyses were performed using SPSS (v. 24.0, IBM Corporation Armonk, NY, USA). All data are presented as mean \pm SD unless otherwise noted. Differences in hydration marker variables between independent variables are presented as mean difference (MD) and 95\% confidence intervals [CI]. Intra-individual means were calculated for each independent variable. Data were grand mean centered and differences in $24 \mathrm{~h}$ hydration status between race/(non-Hispanic black/non-Hispanic white) and sex (male/female) were assessed using repeated measures linear mixed effects models with race and sex as fixed factors. Bonferroni post hoc analyses were conducted when appropriate. Significance was set a-priori at $p<0.05$.

Post hoc power analysis comparing $24 \mathrm{~h}$ urine volume between $\mathrm{WH}$ and BL participants revealed that this study was sufficiently powered to detect an effect size of 2.14; using an alpha level of $p=0.05$, and beta level at $\beta=0.80$, the achieved power was $\beta=0.84$.

\section{Results}

Participant characteristics are shown in Table 1. Across 148 days, participants were classified as underhydrated $54.7 \%(n=81 \mathrm{~d}), 29.7 \%(n=44 \mathrm{~d})$, and $20.9 \%(n=31 \mathrm{~d})$ when using previously defined thresholds for $\mathrm{U}_{\mathrm{OSM}}\left(>500 \mathrm{mOsm} \cdot \mathrm{kg}^{-1}\right), \mathrm{U}_{\mathrm{SG}}(>1.012)$, and $\mathrm{U}_{\mathrm{COL}}(>4)$, respectively. Furthermore, $24 \mathrm{~h} \mathrm{U}_{\mathrm{VOL}}$ exceeded $1.0 \mathrm{~L}, 1.5 \mathrm{~L}$, and $2.0 \mathrm{~L}$ on $62.2 \%(n=92 \mathrm{~d}), 46.6 \%(n=69 \mathrm{~d})$, and $25.0 \%$ $(n=37 \mathrm{~d})$, respectively. No significant differences were observed in $\mathrm{U}_{\mathrm{VOL}}(p=0.113), \mathrm{U}_{\mathrm{OSM}}(p=0.108)$, $\mathrm{U}_{\mathrm{SG}}(p=0.166)$, and $\mathrm{U}_{\mathrm{COL}}(p=0.466)$ between weekdays and weekend days (Table 2)

Table 2. Weekday and weekend day $24 \mathrm{~h}$ urinary hydration measures.

\begin{tabular}{ccccc}
\hline & \multicolumn{2}{c}{ Non-Hispanic White } & \multicolumn{2}{c}{ Non-Hispanic Black } \\
\cline { 2 - 5 } & Weekday & Weekend & Weekday & Weekend \\
\hline Urine Volume (L) & $2.13 \pm 0.73$ & $1.80 \pm 0.57$ & $0.84 \pm 0.42$ & $0.86 \pm 0.47$ \\
Urine Osmolality (mOsm·kg ${ }^{-1}$ ) & $462 \pm 192$ & $498 \pm 198$ & $691 \pm 250$ & $768 \pm 285$ \\
Urine Specific Gravity (AU) & $1.013 \pm 0.005$ & $1.013 \pm 0.006$ & $1.019 \pm 0.006$ & $1.021 \pm 0.007$ \\
Urine Color (AU) & $3.1 \pm 1.2$ & $3.1 \pm 1.2$ & $4.1 \pm 1.4$ & $4.2 \pm 1.5$ \\
\hline
\end{tabular}

Difference in $24 \mathrm{~h}$ hydration variables between BL and WH male and female college students are shown in Table 3. $\mathrm{U}_{\mathrm{VOL}}$ was significantly lower in BL compared to WH college students (MD [95\% CI]; $-1.28 \mathrm{~L}[-1.57,-0.99], p<0.001)$. Conversely, measures of $\mathrm{U}_{\mathrm{OSM}}\left(246 \mathrm{mOsm} \cdot \mathrm{kg}^{-1}[101,390], p=0.001\right)$, $\mathrm{U}_{\mathrm{SG}}(0.007[0.004,0.011], p<0.001)$, and $\mathrm{U}_{\mathrm{COL}}(1.3[0.5,2.1], p=0.002)$, were significantly greater in $\mathrm{BL}$ compared to WH college students (Figure 1).

Table 3. The $24 \mathrm{~h}$ urinary hydration measures between non-Hispanic White and non-Hispanic Black males and females.

\begin{tabular}{ccccc}
\hline & \multicolumn{2}{c}{ Non-Hispanic White } & \multicolumn{2}{c}{ Non-Hispanic Black } \\
\cline { 2 - 5 } & Male $(\boldsymbol{n}=\mathbf{7})$ & Female $(\boldsymbol{n}=\mathbf{3})$ & Male $(\boldsymbol{n}=\mathbf{6})$ & Female $(\boldsymbol{n}=\mathbf{1 6})$ \\
\hline Urine Volume (L) & $1.96 \pm 0.89$ & $2.33 \pm 0.87$ & $0.89 \pm 0.42$ & $0.83 \pm 0.44$ \\
Urine Osmolality (mOsm·kg $\left.{ }^{-1}\right)$ & $492 \pm 195$ & $389 \pm 168$ & $708 \pm 252$ & $719 \pm 268$ \\
Urine Specific Gravity (AU) & $1.013 \pm 0.006$ & $1.010 \pm 0.004$ & $1.020 \pm 0.005$ & $1.020 \pm 0.007$ \\
Urine Color (AU) & $3.2 \pm 1.2$ & $2.2 \pm 0.9$ & $4.4 \pm 1.3$ & $4.1 \pm 1.4$ \\
\hline
\end{tabular}


A.

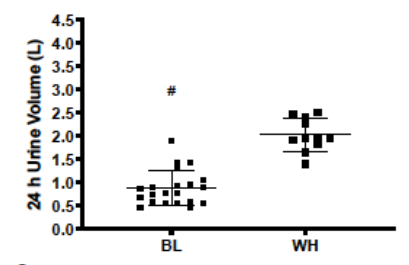

c.

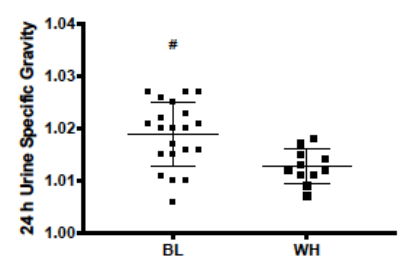

B.

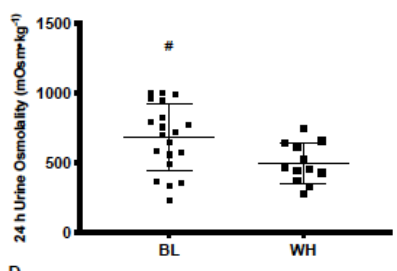

D.

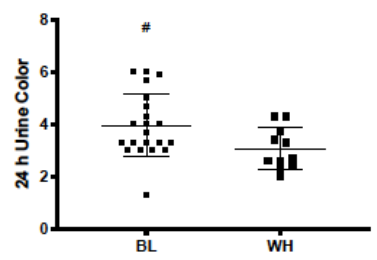

Figure 1. Differences in (A) 24-h urine volume, (B) 24-h urine osmolality, (C) urine specific gravity, and (D) urine color between non-Hispanic Black and non-Hispanic White college-aged males and females. \# indicates statistical significance $(p<0.01)$.

There were no significant differences in $24 \mathrm{~h}$ urinary hydration measures $\left(\mathrm{U}_{\mathrm{VOL}}, p=0.397\right.$; $\mathrm{U}_{\mathrm{OSM}}$, $p=0.942 ; \mathrm{U}_{\mathrm{SG}}, p=0.667 ; \mathrm{U}_{\mathrm{COL}}, p=0.249$ ) between males and females (Table 3). Similarly, there were no significant interactions between race/ethnicity and sex for $\mathrm{U}_{\mathrm{VOL}}(p=0.232), \mathrm{U}_{\mathrm{OSM}}(p=0.571)$, $\mathrm{U}_{\mathrm{SG}}(p=0.550)$, or $\mathrm{U}_{\mathrm{COL}}(p=0.505)$.

\section{Discussion}

This is the first known study that has examined racial and sex differences in $24 \mathrm{~h}$ hydration status in emerging adults. Our findings show that non-Hispanic Black college students, regardless of sex, are inadequately hydrated compared to non-Hispanic white college students when assessing $24 \mathrm{~h}$ urine samples for total volume, osmolality, specific gravity, and color. We found no significant differences between males and females, nor any significant interactions in $24 \mathrm{~h}$ urinary hydration measures between sex and race.

The current study found non-Hispanic Whites to be more hydrated than non-Hispanic Blacks and was confirmed by $24 \mathrm{~h}$ urine volume ( 2.03 vs. $0.85 \mathrm{~L})$, urine osmolality $\left(473 \mathrm{vs.} 716 \mathrm{mOsm} \cdot \mathrm{kg}^{-1}\right)$, urine specific gravity (1.013 vs. 1.020), and urine color (3.0 vs. 4.2). Furthermore, we found that non-Hispanic Blacks were underhydrated, defined by a urine osmolality greater than $500 \mathrm{mOsm} \cdot \mathrm{kg}^{-1}$ [29], on $77.1 \%$ (54/70) of days compared to $34.6 \%$ (27/78) of days for the non-Hispanic White participants in this study. Given prior literature (23), utilizing a $24 \mathrm{~h}$ urine osmolality $<500 \mathrm{mOsm} \cdot \mathrm{kg}^{-1}$ as a threshold of optimal hydration, and increased likelihood of an individual meeting daily adequate intake volumes of water as established by EFSA, we can estimate that $22.9 \%$ of non-Hispanic Blacks and $65.4 \%$ of non-Hispanic Whites in our study were meeting daily water intake requirements. Our findings are in line with others who have found that non-Hispanic Blacks were inadequately hydrated compared to non-Hispanic Whites in a large population based sample [15-17]. While we did not explore reasons that contributed to inter- and intra-individual decisions surrounding daily fluid intake, we speculate that prior life experiences related to knowledge of hydration on health, perceptions of safe drinking water, and availability and accessibility of safe and affordable sources of fluids may have influenced our participants daily fluid consumption as measured by their $24 \mathrm{~h}$ urine sample as suggested in prior work $[17,25,34,35]$.

Other considerations that must not be discounted for potential differences in 24-h urinary hydration measures are the differences in dietary patterns observed between non-Hispanic Black and non-Hispanic White populations [36-38]. Deshmukh-Taskar et al. [36], found that non-Hispanic Blacks consumed more servings of a 'Western Dietary Pattern', reflective of foods that contain less water content than a 'Prudent Dietary Pattern', which includes high water content foods such as fruits and vegetables. 
As approximately $20 \%-25 \%$ of an individual's daily fluid intake comes from food intake [39], differences in dietary patterns may contribute to observed differences in $24 \mathrm{~h}$ urinary hydration measures, however, our current pilot study did not assess for this.

While our study results align with the aforementioned work $[15,16,34]$, our study may be more reflective of one's daily hydration status because we used a $24 \mathrm{~h}$ urine sample across multiple consecutive days for hydration assessment. These methods allow for the capture of individual and daily variation in $24 \mathrm{~h}$ hydration status [21,22,40-42], as well as providing greater clinical utility when guiding recommendations for individual fluid intake for long term health. Interestingly, our findings also show that, within this sample population of college students, there were no differences in $24 \mathrm{~h}$ urinary hydration measures when comparing weekdays and weekend days (Table 2). These findings suggest that $24 \mathrm{~h}$ urinary hydration variables are relatively stable across the week despite potential differences in the structure of weekdays (e.g., class, studying, other school-related responsibilities) compared to weekend days (e.g., employment responsibilities, increased recreational and social activities, etc.).

Our study also found that that there were no differences in $24 \mathrm{~h}$ urine volume, urine osmolality, urine specific gravity and urine color between males and females. Specifically, we found that males and females were hypohydrated (urine osmolality $>500 \mathrm{mOsm} \cdot \mathrm{kg}^{-1}$ ) $50 \%$ and $60.6 \%$ of the time, respectively. This is in contrast to prior work $[43,44]$ that found men to have a higher urine osmolality than women. A potential reason for these contrasting findings is the study populations between studies; our study enrolled non-Hispanic White and non-Hispanic Black college students whereas the aforementioned work studied older Portuguese men and women. Given the observed geographical differences in habitual fluid intake across the lifespan $[27,28]$ and the known changes in habitual fluid intake as one ages $[26,45-48]$, the generalizability of previous work to the current study may be limited.

Another explanation to account for the lack of observed differences in $24 \mathrm{~h}$ urinary hydration status when comparing sex and the interaction of sex and race is the distribution in sample size in the current study, particularly with the number of female participants. Nineteen non-Hispanic Black females completed the current study compared to the three non-Hispanic White females. Given the statistically significant differences in $24 \mathrm{~h}$ hydration status based on race/ethnicity in our study, the unequal sample sizes may have prevented us from elucidating the influence of sex and ethnicity on $24 \mathrm{~h}$ urinary hydration measures.

The strengths of the current study are the utilization of $24 \mathrm{~h}$ urine samples across consecutive days to examine inter- and intra-individual differences in daily hydration status. These measures are informative surrounding daily fluid intake and whether individuals are meeting daily intake recommendations. By assessing $24 \mathrm{~h}$ urinary hydration variables, we are able to minimize the influence of sex and race/ethnicity and the systematic variation in urinary flow rate as observed in assessment of spot samples [49], thus providing a more accurate depiction of racial and sex differences in urinary hydration variables. Furthermore, given the differences observed in fluid intake between sex, race/ethnicity, and levels of physical activity [17], the examination of $24 \mathrm{~h}$ urinary hydration measures is an important indicator of hydration status as it represents the behavioral and neuroendocrine responses that are regulated by fluid intake and normalizes any differences in body size, body composition, physical activity level, and solute load, which is difficult to control for in population-based studies. This study also represents the first step in further exploring racial and ethnic differences in daily hydration status; examination of sociocultural differences, social determinants of drinking behavior, and effects of daily fluid intake on health outcomes, particularly in populations with known health disparities is the strategic next step to further our understanding on this topic.

Our study, however, is not without limitations. Utilizing a convenience sample of male and female college students from a large university in the southeastern part of the United States may not be generalizable to emerging adults from differing geographical, cultural, racial, and ethnic backgrounds. Furthermore, as we collected data throughout the academic year, we may not have been able to control for any acute changes in fluid intake behaviors that may have occurred in any one individual. 
Given the pilot nature of this work, we did not collect data related to daily fluid, or dietary intake and physical activity. Seeing as the former contributes to urine output across a $24 \mathrm{~h}$ period, prior evidence [47] suggests that a $24 \mathrm{~h}$ urine sample is a sufficient surrogate for daily fluid intake. Lastly, we must acknowledge that there is a potential that participants may not have provided a $24 \mathrm{~h}$ urine sample on each day; there may have been a missed void for a number of reasons. We feel the latter is of minimal concern considering our collection procedures required multiple and consecutive days of $24 \mathrm{~h}$ urine collection, thus we are confident that we were able to capture a representative average for each participant.

In conclusion, our findings show that a sample of non-Hispanic Black college students (particularly females) from the southeast part of the United States are inadequately hydrated compared to their non-Hispanic White counterparts. Furthermore, these findings show that Black male and female college students are not likely meeting recommended daily water intake volumes. Future research examining factors influencing the role of habitual fluid intake on health outcomes in populations with known health disparities such as obesity, cardiovascular disease, type II diabetes mellitus, etc. is needed to continue to develop proper prevention and management strategies to optimize long-term health.

Author Contributions: W.M.A., J.P.M., and J.T.M. conceptualized the design and methodology of this study. W.M.A., J.P.M., J.T.M., and D.J.H. were responsible for data curation. W.M.A. was responsible for the initial analysis and writing of the original draft of the manuscript. J.P.M., J.T.M., and D.J.H. were responsible for critically reviewing the manuscript. W.M.A., J.P.M., J.T.M., and D.J.H. provided final approval of the manuscript prior to submission. All authors have read and agreed to the published version of the manuscript.

Funding: This project was supported in part by the Research Excellence Grant awarded by the School of Health and Human Sciences at the University of North Carolina at Greensboro. The APC was funded on behalf of Nutrients.

Acknowledgments: We would like to acknowledge the following individuals for their assistance with this project: Stacey L. Walton, Eleni M. Karras, Gabrielle S. Glenn, Megan L. Haskins, and Amber Huntsinger.

Conflicts of Interest: The authors have no conflicts of interest to disclose. The results of this study are presented clearly, honestly and without falsification, fabrication or inappropriate data manipulation.

\section{References}

1. Armstrong, L.E. Assessing hydration status: The elusive gold standard. J. Am. Coll Nutr. 2007, 26 (Suppl. 5), 575S-584S. [CrossRef] [PubMed]

2. Oppliger, R.A.; Bartok, C. Hydration testing of athletes. Sports Med. 2002, 32, 959-971. [CrossRef]

3. Manz, F.; Wentz, A. 24-h hydration status: Parameters, epidemiology and recommendations. Eur. J. Clin. Nutr. 2003, 57 (Suppl. 2), S10-S18. [CrossRef]

4. Agostoni, C.V.; Bresson, J.L.; Fairweather Tait, S.; Flynn, A.; Golly, I.; Korhonen, H.; Moseley, B. Scientific Opinion on Dietary Reference Values for water. EFSA J. 2010, 8. [CrossRef]

5. Daniels, M.C.; Popkin, B.M. Impact of water intake on energy intake and weight status: A systematic review. Nutr. Rev. 2010, 68, 505-521. [CrossRef]

6. Schwartz, A.E.; Leardo, M.; Aneja, S.; Elbel, B. Effect of a School-Based Water Intervention on Child Body Mass Index and Obesity. JAMA Pediatr. 2016, 170, 220-226. [CrossRef] [PubMed]

7. Su, S.-B.; Wang, J.-N.; Lu, C.-W.; Guo, H.-R. Reducing urinary tract infections among female clean room workers. J. Womens Health 2002 2006, 15, 870-876. [CrossRef] [PubMed]

8. Roussel, R.; Fezeu, L.; Bouby, N.; Balkau, B.; Lantieri, O.; Alhenc-Gelas, F.; DESIR Study Group. Low water intake and risk for new-onset hyperglycemia. Diabetes Care. 2011, 34, 2551-2554. [CrossRef]

9. Clark, W.F.; Sontrop, J.M.; Macnab, J.J.; Suri, R.S.; Moist, L.; Salvadori, M.; Garg, A.X. Urine Volume and Change in Estimated GFR in a Community-Based Cohort Study. Clin. J. Am. Soc. Nephrol. 2011, 6, 2634-2641. [CrossRef]

10. Sontrop, J.M.; Dixon, S.N.; Garg, A.X.; Buendia-Jimenez, I.; Dohein, O.; Huang SH, S.; Clark, W.F. Association between water intake, chronic kidney disease, and cardiovascular disease: A cross-sectional analysis of NHANES data. Am. J. Nephrol. 2013, 37, 434-442. [CrossRef] 
11. Hooton, T.M.; Vecchio, M.; Iroz, A.; Tack, I.; Dornic, Q.; Seksek, I.; Lotan, Y. Effect of Increased Daily Water Intake in Premenopausal Women with Recurrent Urinary Tract Infections: A Randomized Clinical Trial. JAMA Intern. Med. 2018. [CrossRef] [PubMed]

12. Ferreira-Pêgo, C.; Guelinckx, I.; Moreno, L.A.; Kavouras, S.A.; Gandy, J.; Martinez, H.; Babio, N. Total fluid intake and its determinants: Cross-sectional surveys among adults in 13 countries worldwide. Eur. J. Nutr. 2015, 54 (Suppl. 2), 35-43.

13. Liska, D.; Mah, E.; Brisbois, T.; Barrios, P.L.; Baker, L.B.; Spriet, L.L. Narrative Review of Hydration and Selected Health Outcomes in the General Population. Nutrients 2019, 11, 70. [CrossRef] [PubMed]

14. Perrier, E.T. Shifting Focus: From Hydration for Performance to Hydration for Health. Ann. Nutr. Metab. 2017, 70 (Suppl. 1), 4-12. [CrossRef]

15. Brooks, C.J.; Gortmaker, S.L.; Long, M.W.; Cradock, A.L.; Kenney, E.L. Racial/Ethnic and Socioeconomic Disparities in Hydration Status Among US Adults and the Role of Tap Water and Other Beverage Intake. Am. J. Public Health 2017, 107, 1387-1394. [CrossRef]

16. Kenney, E.L.; Long, M.W.; Cradock, A.L.; Gortmaker, S.L. Prevalence of Inadequate Hydration Among US Children and Disparities by Gender and Race/Ethnicity: National Health and Nutrition Examination Survey, 2009-2012. Am. J. Public Health. 2015, 105, e113-e118. [CrossRef]

17. Rosinger, A.; Herrick, K. Daily Water Intake Among, U.S. Men and Women, 2009-2012. NCHS Data Brief 2016, 242, 1-8.

18. Cheuvront, S.N.; Kenefick, R.W.; Zambraski, E.J. Spot Urine Concentrations Should Not be Used for Hydration Assessment: A Methodology Review. Int. J. Sport Nutr. Exerc. Metab. 2015, 25, 293-297. [CrossRef]

19. Cheuvront, S.N.; Ely, B.R.; Kenefick, R.W.; Sawka, M.N. Biological variation and diagnostic accuracy of dehydration assessment markers. Am. J. Clin. Nutr. 2010, 92, 565-573. [CrossRef]

20. Bottin, J.H.; Lemetais, G.; Poupin, M.; Jimenez, L.; Perrier, E.T. Equivalence of afternoon spot and 24-h urinary hydration biomarkers in free-living healthy adults. Eur. J. Clin. Nutr. 2016, 70, 904-907. [CrossRef]

21. Perrier, E.; Demazières, A.; Girard, N.; Pross, N.; Osbild, D.; Metzger, D.; Klein, A. Circadian variation and responsiveness of hydration biomarkers to changes in daily water intake. Eur. J. Appl. Physiol. 2013, 113, 2143-2151. [CrossRef] [PubMed]

22. Armstrong, L.E.; Pumerantz, A.C.; Fiala, K.A.; Roti, M.W.; Kavouras, S.A.; Casa, D.J.; Maresh, C.M. Human hydration indices: Acute and longitudinal reference values. Int. J. Sport Nutr. Exerc. Metab. 2010, 20, 145-153. [CrossRef] [PubMed]

23. Perrier, E.T.; Buendia-Jiminez, I.; Vecchio, M.; Armstrong, L.E.; Tack, I.; Klein, A. Twenty-Four-Hour Urine Osmolality as a Physiological Index of Adequate Water Intake. Dis. Markers 2015. [CrossRef] [PubMed]

24. Johnson, E.C.; Péronnet, F.; Jansen, L.T.; Capitan-Jiménez, C.; Adams, J.D.; Guelinckx, I.; Kavouras, S.A. Validation Testing Demonstrates Efficacy of a 7-Day Fluid Record to Estimate Daily Water Intake in Adult Men and Women When Compared with Total Body Water Turnover Measurement. J. Nutr. 2017, 147, 2001-2007. [CrossRef]

25. Perrier, E.; Vergne, S.; Klein, A.; Poupin, M.; Rondeau, P.; Le Bellego, L.; Tack, I. Hydration biomarkers in free-living adults with different levels of habitual fluid consumption. Br. J. Nutr. 2013, 109, 1678-1687. [CrossRef]

26. Perrier, E.; Rondeau, P.; Poupin, M.; Le Bellego, L.; Armstrong, L.E.; Lang, F.; Stookey, J.; Tack, I.; Vergne, S.; Klein, A. Relation between urinary hydration biomarkers and total fluid intake in healthy adults. Eur. J. Clin. Nutr. 2013, 67, 939-943. [CrossRef]

27. Guelinckx, I.; Ferreira-Pêgo, C.; Moreno, L.A.; Kavouras, S.A.; Gandy, J.; Martinez, H.; Bardosono, S.; Abdollahi, M.; Nasseri, E.; Jarosz, A.; et al. Intake of water and different beverages in adults across 13 countries. Eur. J. Nutr. 2015, 54 (Suppl. 2), 45-55. [CrossRef]

28. Guelinckx, I.; Iglesia, I.; Bottin, J.H.; De Miguel-Etayo, P.; González-Gil, E.M.; Sala-Salvadó, J.; Kavouras, S.A.; Gandy, J.; Martinez, H.; Bardosono, S.; et al. Intake of water and beverages of children and adolescents in 13 countries. Eur. J. Nutr. 2015, 54 (Suppl. 2), 69-79. [CrossRef]

29. Armstrong, L.E.; Maresh, C.M.; Castellani, J.W.; Bergeron, M.F.; Kenefick, R.W.; LaGasse, K.E.; Riebe, D. Urinary indices of hydration status. Int. J. Sport Nutr. 1994, 4, 265-279. [CrossRef]

30. Perrier, E.T.; Bottin, J.H.; Vecchio, M.; Lemetais, G. Criteriorn values for urine specific gravity and urine color representing adequate water intake in health adults. Eur. J. Clin. Nutr. 2017, 71, 561-563. [CrossRef] 
31. Jackson, A.S.; Pollock, M.L. Generalized equations for predicting body density of men. Br. J. Nutr. 1978, 40, 497-504. [CrossRef] [PubMed]

32. Jackson, A.S.; Pollock, M.L.; Ward, A. Generalized equations for predicting body density of women. Med. Sci. Sports Exerc. 1980, 12, 175-181. [CrossRef] [PubMed]

33. Siri, W.E. Body composition from fluid spaces and density: Analysis of methods. 1961. Nutr. Burbank Los. Angel. Cty Calif. 1993, 9, 480-491.

34. Rosinger, A.Y.; Herrick, K.A.; Wutich, A.Y.; Yoder, J.S.; Ogden, C.L. Disparities in plain, tap and bottled water consumption among US adults: National Health and Nutrition Examination Survey (NHANES) 2007-2014. Public Health Nutr. 2018, 21, 1455-1464. [CrossRef]

35. Rosinger, A.Y. Biobehavioral variation in human water needs: How adaptations, early life environments, and the life course affect body water homeostasis. Am. J. Hum. Biol Off. J. Hum. Biol Counc. 2020, 32, e23338. [CrossRef]

36. Deshmukh-Taskar, P.R.; O’Neil, C.E.; Nicklas, T.A.; Yang, S.; Liu, Y.; Gustat, J.; Berenson, G.S. Dietary patterns associated with metabolic syndrome, sociodemographic and lifestyle factors in young adults; the Bogalusa Heart Study. Public Health Nutr. 2009, 12, 2493-2503. [CrossRef]

37. Kant, A.K.; Graubard, B.I.; Kumanyika, S.K. Trends in Black-White Differentials in Dietary Intakes of U.S. Adults, 1971-2002. Am. J. Prev. Med. 2007, 32, 264-272. [CrossRef]

38. Kant, A.K.; Graubard, B.I. 20-Year Trends in Dietary and Meal Behaviors Were Similar in U.S. Children and Adolescents of Different Race/Ethnicity. J. Nutr. 2011, 141, 1880-1888. [CrossRef]

39. Institute of Medicine. Dietary Reference Intakes for Water, Potassium, Sodium, Chloride, and Sulfate; The National Academies Press: Washington, DC, USA, 2005.

40. Chang, T.; Ravi, N.; Plegue, M.A.; Sonneville, K.R.; Davis, M.M. Inadequate Hydration, BMI, and Obesity Among US Adults: NHANES 2009-2012. Ann. Fam. Med. 2016, 14, 320-324. [CrossRef]

41. Armstrong, L.E.; Johnson, E.C.; Munoz, C.X.; Swokla, B.; Le Bellego, L.; Jiminez, L.; Casa, D.J.; Maresh, C.M. Hydration biomarkers and dietary fluid consumption of women. J. Acad. Nutr. Diet. 2012, 112, 1056-1061. [CrossRef]

42. Padez, C.; Padrão, P.; Macedo, A.; Santos, A.; Gonçalves, N. Caracterização do aporte hídrico dos portugueses. Nutrícias Rev. Assoc. Port. Nutr. 2009, 9, 25-27.

43. Padrão, P.; Sousa, A.S.; Guerra, R.S.; Álvares, L.; Santos, A.; Borges, N.; Afonso, C.; Amaral, T.F.; Moreira, P. A Cross-Sectional Study on the Association between 24-h Urine Osmolality and Weight Status in Older Adults. Nutrients 2017, 9, 1272. [CrossRef]

44. Yates, B.A.; Ellis, L.A.; Butts, C.L.; McDermott, B.P.; Williamson, K.H.; Armstrong, L.E. Factors Associated with Pre-Event Hydration Status and Drinking Behavior of Middle-Aged Cyclists. J. Nutr. Health Aging 2018, 22, 335-340. [CrossRef] [PubMed]

45. Crowe, M.J.; Forsling, M.L.; Rolls, B.J.; Phillips, P.A.; Ledingham, J.G.G.; Smith, R.F. Altered Water Excretion Inhealthy Elderly Men. Age Ageing. 1987, 16, 285-293. [CrossRef] [PubMed]

46. Phillips, P.A.; Rolls, B.J.; Ledingham, J.G.G.; Forsling, M.L.; Morton, J.J.; Crowe, M.J.; Wollner, J. Reduced Thirst after Water Deprivation in Healthy Elderly Men. N. Engl. J. Med. Boston. 1984, 311, 753-759. [CrossRef] [PubMed]

47. Phillips, P.A.; Bretherton, M.; Risvanis, J.; Casley, D.; Johnston, C.; Gray, L. Effects of drinking on thirst and vasopressin in dehydrated elderly men. Am. J. Physiol.-Regul. Integr. Comp. Physiol. 1993, 264, R877-R881. [CrossRef]

48. Phillips, P.A.; Bretherton, M.; Johnston, C.I.; Gray, L. Reduced osmotic thirst in healthy elderly men. Am. J. Physiol.-Regul. Integr. Comp. Physiol. 1991, 261, R166-R171. [CrossRef]

49. Hays, S.M.; Aylward, L.L.; Blount, B.C. Variation in Urinary Flow Rates According to Demographic Characteristics and Body Mass Index in NHANES: Potential Confounding of Associations between Health Outcomes and Urinary Biomarker Concentrations. Env. Health Perspec. 2015, 123, 293-300. [CrossRef]

(C) 2020 by the authors. Licensee MDPI, Basel, Switzerland. This article is an open access article distributed under the terms and conditions of the Creative Commons Attribution (CC BY) license (http://creativecommons.org/licenses/by/4.0/). 